FACULdADE DE CIÊNCIAS ECONÔ MICAS DA UFRGS

MACROECONOMIA DO BRASIL PÓS-1994 LUIZ CARLOS BRESSER-PEREIRA

DESENVOLVIMENTO ECONOMMICO, PREFERÊNCIA PELA LIQUIDEZ E ACESSO BANCÁRIO: UM ESTUDO DE CASO DAS MESORREGIÓES DE MINAS GERAIS

MARCO CROCCO, CLAUDIO BARRA DE CASTRO, ANDERSON CAVALCANTE E VANESSA DA COSTA VAL

FRIEDMAN E O MONETARISMO: A VELHA TEORIA QUANTITATIVA DA MOEDA E A MODERNA ESCOLA MONETARISTA

GENTIL CORAZZAE RODRIGO L. KREMER

BOLLHAS RACIONAIS, CICLO DE PREÇOS DE ATIVOS E RACIONALIDADE LIMITADA: UMA AVALIACAOO CRITICA DOS MODELOS NEOCLÁSSICOS DE BOLHAS ESPECULATIVAS JOSÉ LUIS OREIRO

VULNERABILITY INDICATORS OF THE TWIN CRISES: THE EAST ASIAN EPISODE

TITO BELCHIOR SILVA MOREIRA

IMPACTOS POTENCIAIS DA NEGOCIAÇÃO DA ALCA SOBRE OS INVESTIMENTOS EXTERNOS EM SERVIÇOS PROFISSIONAIS NO BRASIL

MICHEL ALEXANDRE, OTAVIANO CANUTO E GILBERTO TADEU LIMA

TEORIA MARXISTA DO VALOR: UMA INTRODUÇẢO ALFREDO SAAD FILHO

UM ESTUDO EMPIRICO DOS CICLOS POLITICO. ECONOOMICOS NO BRASIL

ATHOS PRATES DA SILVEIRA PREUSSLER E MARCELO SAVINO PORTUGAL

RELENDO CHANDLER, WILLIAMSON E NORTH PARA ENTENDER O PROCESSO DE FORMACĀO DAS ESTRADAS DE FERRO NO BRASIL

JEFFERSON ANDRONIO RAMUNDO STADUTO

WEIMAR FREIRE DA ROCHA IR. E CLAIITON ATAIDES DE FREITAS

MATRIZ DE INSUMO-PRODUTO PARA A ECONOMIA TURISTICA BRASILEIRA: CONSTRUCCÃO E ANÁLISE DAS RELAÇÓES INTERSETORIAIS

FRANCISCO CASIMIRO FILHO E JOAQUIM JOSÉ MARTINS GUILHOTO

SEÇĀO ESPECIAL: AVALIAÇŌES INICIAIS DA POLITTICA ECONÓMICA DO GOVERNO LULA

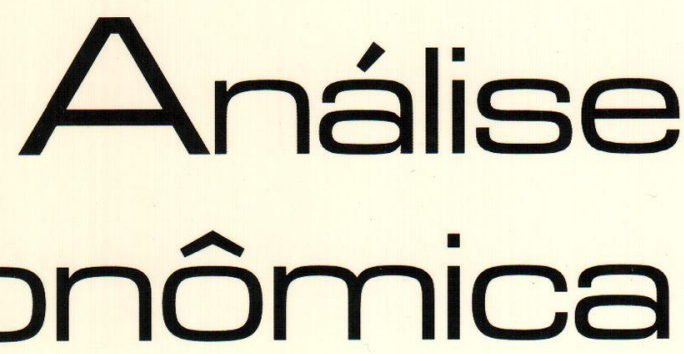


Universidade Federal do Rio Grande do Sul

Reitora: Profa. Wrana Maria Panizzi

Faculdade de Ciencias EConómicas

Diretora: Prof Pedro César Dutra Fonseca

Centro de Estudos e Pesquisas Economicas

Diretor: Prof. Gentil Corazza

Departamento de Ciéncias económicas

Chiefe: Prof. Ricardo Dathein

Curso de Pós. Graduação em Economia

Coordenador: Prof. Eduardo Pontual Ribeiro

Programa de Pós-Graduação em Desenvolvimento Rural

Coordenador: Prof. jalcione Almeida

CONSElHo EDITORIAL:

Carlos G. A. Mielitz Netto (UFRGS), Eduardo A. Maldonado Filho (UFRGS), Eduardo P. Ribeiro (UFRGS), Eleutério F. S. Prado (USP), Eugênio Lagemann (UFRGS), Fernando Cardim de Carvalho (UFRJ), Fernando Ferrari Filho (UFRGS), Fernando de Holanda Barbosa (FGV/RJ), Flávio Vasconcellos Comim (UFRGS), Gentil Corazza (UFRGS), Giácomo Balbinotto Netto (UFRGS), Gustavo Franco (PUC/RJ), Jan A. Kregel (UNCTAD), João Rogério Sanson (UFSC), Joaquim Pinto de Andrade (UnB), Jorge Paulo Araújo (UFRGS), Marcelo S. Portugal (UFRGS), Maria Alice Lahorgue (UFRGS), Paul Davidson (University of Tennessee), Paulo D. Waquil (UFRGS), Pedro C. D. Fonseca (UFRGS), Philip Arestis (Levy Economics Institut of Bard College), Roberto C. de Moraes (UFRGS), Ronald Otto Hillbrecht (UFRGS), Sabino da Silva Porto Jr. (UFRGS), Stefano Florissi (UFRGS) e Werner Baer (University of Illinois at UrbanaChampaign).

COMISSÃO EDITORIAL:

Eduardo Augusto Maldonado Filho, Fernando Ferrari Filho, Gentil Corazza, Marcelo Savino Portugal, Paulo Dabdab Waquil e Roberto Camps Moraes.

EDIroR: Prof. Fernando Ferrari Filho

Editor Adunnio: Prof. Gentil Corazza

SECRETÁrla: Clarissa Roncato Baldim

REVISÁO DE TEXTOS: Vanete Ricacheski

EDITORaÇão Eletrónica: Vanessa Hoffmann de Quadros

Fundador: Prof Antônio Carlos Santos Rosa

Os materiais publicados na revista Análise Econômica são da exclusiva responsabilidade dos autores. É permitida a reprodução total ou parcial dos trabalhos, desde que seja citada a fonte. Aceita-se permuta com revistas congêneres. Aceitam-se, também, livros para divulgação, elaboraçāo de resenhas e recensōes Toda correspondência, material para publicaçāo (vide normas na terceira capa), assinaturas e permutas devem ser dirigidos ao seguinte destinatário:

Análise Econômico

PROF FERNANDO FERRARI FILHO Revisła Análise Econômica - Av. João Pessoa, 52 CEP 90040-000 PORTO ALEGRE - RS, BRASL Telefones: (051) 316-3513 - Fax: (051) 316-3990 E-mail: rae@ufrgs.br

Ano 21, $n^{\circ} 39$, março, 2003 - Porto Alegre

Faculdade de Ciências Econômicas, UFRGS, 2003

Periodicidade semestral, março e setembro.

Tiragem: 500 exemplares

1. Teoria Econômica - Desenvolvimento Regional.

Economia Agrícola - Pesquisa Teórica e Aplicada -

Periódicos. I. Brasil

Faculdade de Ciências Econômicas,

Universidade Federal do Rio Grande do Sul 


\title{
Um Estudo Empírico dos Ciclos Político-Econômicos no Brasil
}

\author{
Athos Prates da Silveira Preussler' \\ Marcelo Savino Portugal ${ }^{2}$
}

\begin{abstract}
The political business cycle theory suggests that economic fluctuations can be explained by the electoral calendar. Knowing that economic performance has great influence in the electorate vote decision, the incumbent may try to manipulate the economy policy in order to maximize the chances of victory of the government candidate. Empirical studies that aimed to test this hypothesis have found evidence of political opportunism as much on macroeconomic variables as on the political economy instruments. The present paper has the objective to test the hypothesis of political opportunism on macroeconomic variables, on fiscal policy instruments and interest rates in Brazil between 1980 and 2000. The econometric tests we will use autoregressive integrated moved average models (ARIMA) with intercept dummy variables in the months that precede the elections. The results confirm the hypothesis of political opportunism in the inflation rate and in the total expenditure of the federal government.
\end{abstract}

Key Words: political business cycle; political economy; economic policy. JEL Classification: E60.

\section{Introdução}

A hipótese de que o desempenho da economia tem influência direta sobre o resultado das eleiçōes é inegável. Dificilmente, algum político teria a coragem de anunciar um aumento de impostos, uma política econômica restritiva ou uma desvalorização do câmbio às vésperas de uma eleição. Apesar de se tratar de uma proposta bastante intuitiva, a relação entre a conjuntura econômica e o calendário eleitoral somente passou a ser estudada com maior intensidade a partir de meados dos anos 70, com o advento da teoria dos ciclos político-econômicos. De acordo com essa concepção, os ciclos econômicos são gerados pelo comportamento oportunista dos

\footnotetext{
1 Analista de Finanças e Controle da Secretaria do Tesouro Nacional (AFC/STN).

2 Professor do Programa de Pós-Graduação em Economia da UFRGS e pesquisador do CNPq.
} 
policymakers que manipulam os instrumentos de política econômica a fim de melhorar os indicadores econômicos e obter a vitória nas urnas.

O presente artigo pretende investigar a ocorrência dos ciclos político-econômicos nas variáveis macroeconômicas, nos instrumentos de política fiscal e na taxa de juros do Brasil entre 1980 e 2000 . Nas seções 2 e 3, discutimos os principais fundamentos da teoria dos ciclos político-econômicos. Na quarta seção, fazemos uma revisão dos estudos empíricos que visaram testar as proposições dos modelos teóricos. Na seção seguinte, descrevemos a metodologia do procedimento econométrico. Na seção 6, verificamos a existência de oportunismo político nas variáveis macroeconômicas. Na seção 7, buscamos evidências de manipulação pré-eleitoral dos instrumentos de política macroeconômica. Finalmente, na última seção, apresentamos as conclusões do artigo.

\section{A Teoria dos Ciclos Político-Econômicos}

A idéia tradicional de que os responsáveis pela política econômica são indivíduos solidários que tomam medidas visando única e exclusivamente à maximização do bem-estar social passou a ser contestada com mais intensidade após a publicação do trabalho de Downs (1957). Segundo o autor, os modelos que adotam a maximização do bem-estar social entre seus pressupostos estão equivocados, pois não há uma definição clara do que venha a ser "bemestar social" e, mesmo que fosse possível defini-lo, seria difícil acreditar que os responsáveis pelas políticas públicas são seres benevolentes, cujas decisões não são influenciadas por seus desejos individuais.

Baseada na crítica de Downs (1957), em meados dos anos 70, surgiu a teoria dos ciclos político-econômicos (political business cycles theory), que relaciona as flutuações econômicas aos eventos políticos. De acordo com essa concepção, os policymakers desviam a condução da política econômica do "socialmente ótimo" a fim de atender aos seus próprios interesses. Ao analisarmos a literatura, podemos identificar diferentes interpretações quanto à motivação dos policymakers ao escolher determinadas políticas públicas. Enquanto um grupo de modelos supõe que os policymakers sejam movidos por alguma ideologia partidária, outro grupo parte da premissa que estes agem por puro oportunismo, almejando apenas a vitória nas urnas. 


\subsection{Modelos Oportunistas}

Os modelos de ciclos político-econômicos oportunistas foram desenvolvidos a partir do artigo inovador de Nordhaus (1975). Conforme essa proposta, com a proximidade das eleições, os policymakers sentir-se-ão tentados a manipular os instrumentos de política econômica, a fim de expandir a economia e desenhar o cenário econômico ideal para conseguir a reeleição do governante ou a manutenção do seu partido no poder. Passado o período eleitoral, os policymakers tomarão medidas para reverter os efeitos adversos da política econômica implementada anteriormente. Sendo assim, ao analisarmos a trajetória das variáveis macroeconômicas, deveríamos observar a ocorrência de um ciclo econômico, no qual os pontos de inflexão coincidem com o calendário eleitoral.

\section{Gráfico 1: O Ciclo Político-Econômico Oportunista}

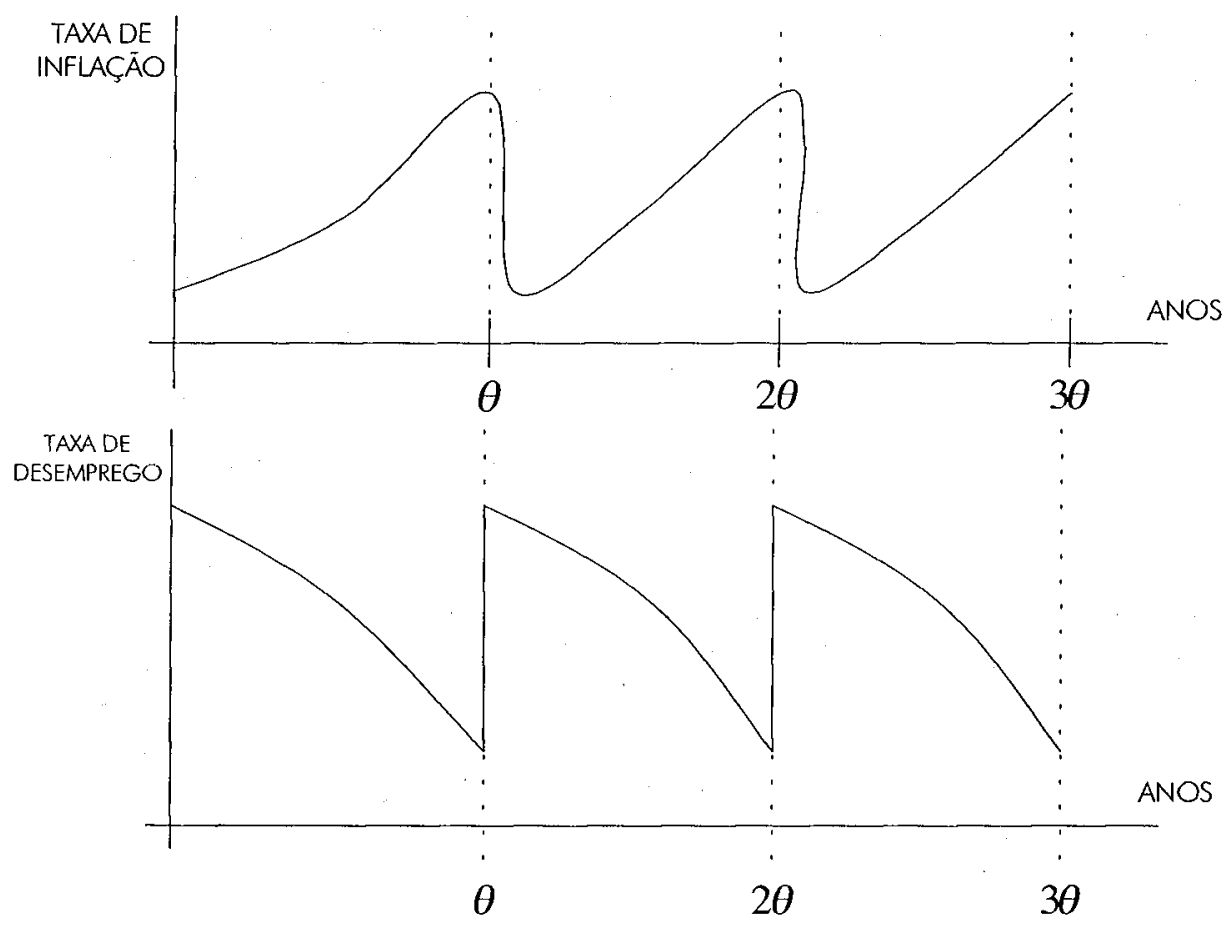


Os modelos oportunistas tradicionais ${ }^{3}$ foram elaborados numa época em que prevalecia a crença de que a economia seria caracterizada por uma curva de Phillips de curto prazo, perfeitamente explorável pelos responsáveis pela política econômica. A existência do trade-off permanente entre inflação e desemprego era viabilizada pela hipótese de que os agentes econômicos teriam expectativas adaptativas. Desta forma, aos policymakers bastava observar as preferências dos eleitores por inflação e desemprego, representadas por funções de desutilidade, e escolher a combinação ótima que maximizaria a quantidade de votos necessários para garantir a reeleição.

Analisando o gráfico 1 , podemos verificar a forma que o ciclo político-econômico proposto por Nordhaus (1975) se manifesta. A taxa de desemprego deve ser decrescente ao longo de todo o mandato, subindo a um nível relativamente elevado imediatamente após a eleiçāo, para conter o aumento do nível de preços e modificar as expectativas inflacionárias dos agentes. Observamos que mesmo que no instante da eleição $(t=\theta)$ a inflação seja bastante elevada, o governante conseguirá se reeleger, pois a desutilidade marginal do desemprego para o eleitor representativo no modelo de Norhaus (1975) é maior que a desutilidade marginal da inflação ${ }^{4}$.

\subsection{Modelos Partidários}

Ao pressuporem que os políticos são idênticos, tendo como única motivação a permanência no poder e que isto guiaria a condução da política econômica, os modelos oportunistas tradicionais ignoraram a influência da ideologia partidária sobre essas decisões. Como os partidos representam a união de indivíduos que comungam dos mesmos interesses e preferências, é de se esperar que as suas ideologias sejam refletidas na maneira com a qual cada partido conduz a política econômica quando estiver no poder. Acreditando nessa hipótese, foram desenvolvidos modelos que incorporaram o componente de ideologia partidária à teoria dos ciclos político-econômicos, denominados modelos partidários.

\footnotetext{
3 Ver Lindbeck (1976) e MacRae (1977).

4 Caso estivéssemos modelando as preferências do eleitor representativo alemão na época da hiperinflação ou de um brasileiro na década de 80 , com certeza a desurilidade marginal da taxa de inflação seria maior do que a da taxa de desemprego.
} 
Num artigo bastante influente, Hibbs (1977) estimou um modelo para verificar a existência de diferenças partidárias na condução da política econômica e dos resultados macroeconômicos para os Estados Unidos e Inglaterra. O autor constatou que os partidos de di-reita enfatizam a estabilidade monetária, enquanto os partidos de esquerda priorizam a redução da taxa de desemprego. Na opinião do autor, isso ocorre porque os partidos de direita representam os interesses das classes mais abastadas, seus membros possuem a maior parte do capital financeiro e acumulam maiores perdas com a elevação da inflação, enquanto que os partidos de esquerda são formados por indivíduos das classes trabalhadoras, mais sensíveis ao aumento do desemprego 5 .

\section{Gráfico 2: Modelo de Ciclo Político-Econômico Partidário}

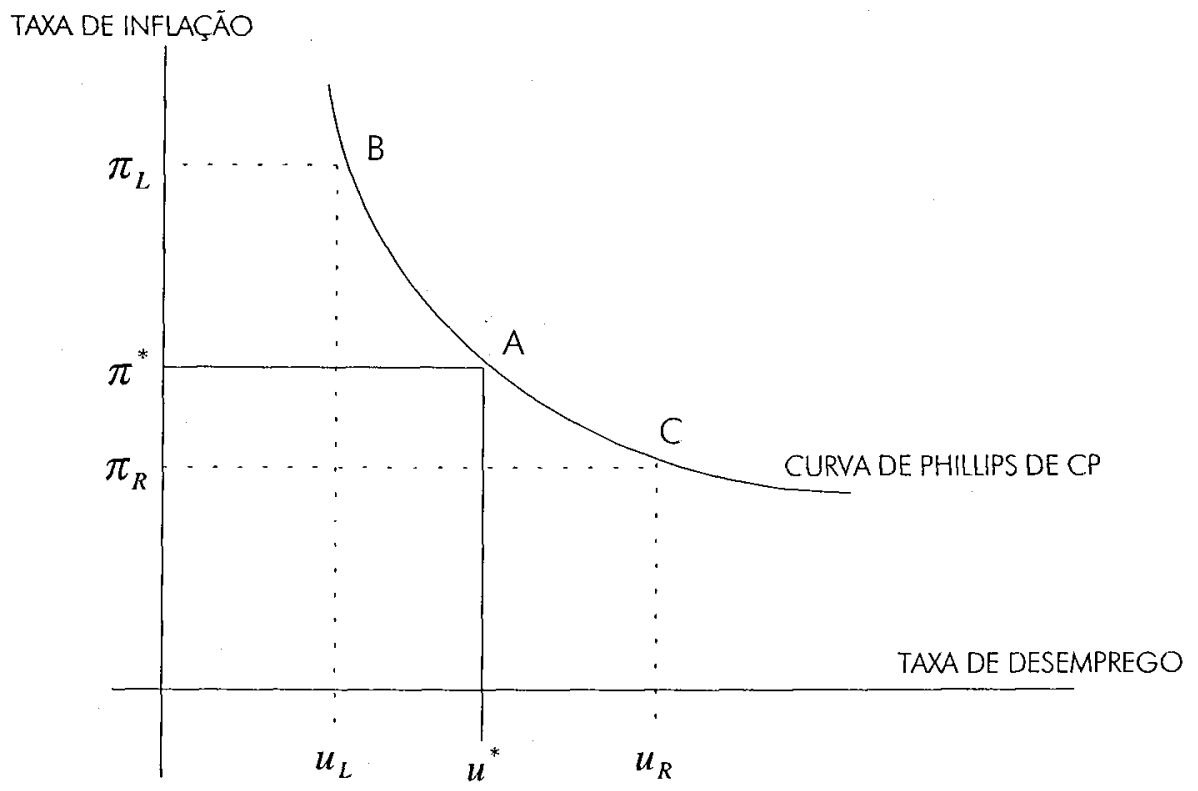

\footnotetext{
${ }^{5}$ Hibbs (1977) parece ignorar que os assalariados sâo os maiores prejudicados com o aumento do nivel geral de preços, pois possuem uma menor parte da sua renda investida em ativos que lhes protejam da inflação.
} 
Como o trabalho de Hibbs (1977 e 1986) tem um caráter eminentemente empírico, não é apresentada uma modelagem teórica formal das suas hipóteses. Apesar disso, podemos constatar que, da mesma forma que os modelos oportunistas, o seu modelo é aplicado num sistema econômico representado por uma curva de Phillips com expectativas adaptativas, no qual os policymakers possuem controle total sobre os instrumentos de política econômica e podem escolher a combinação de inflação e desemprego desejada.

O autor conclui que, ao observarmos o comportamento das variáveis macroeconômicas, notaremos a presença de um ciclo gerado por diferentes partidos alternando-se no poder. Supondo que a economia encontra-se inicialmente no pleno emprego $\left(u^{*}\right)$, representado no gráfico 2 pelo ponto $A$. Caso um partido de direita vença as eleições, como a prioridade será a redução da inflação até o nível $\pi_{R}$, a política econômica será restritiva e haverá um aumento do desemprego $\left(u_{R}\right)$, como no ponto $C$. Por outro lado, se um partido de esquerda assumir o poder, a política econômica será conduzida de uma maneira mais "frouxa", pois o objetivo é a redução do desemprego até $u_{L}$, representado pelo ponto $B$, o que irá gerar um processo inflacionário $\left(\pi_{L}\right)$.

\section{Modelos de Ciclos Político-Econômicos com Expectativas Racionais}

Com o advento das expectativas racionais, os modelos de ciclos político-econômicos tiveram que ser reformulados, pois, sob essa hipótese, a premissa de que os eleitores são indivíduos ingênuos, incapazes de aprender e propensos a erros sistemáticos, torna-se insatisfatória. Uma vez que o eleitor tenha presenciado um ciclo político-econômico, não será mais ludibriado por políticos oportunistas, pois tem consciência de que um aumento da atividade econômica no período pré-eleitoral será seguido por uma elevação do nível de preços e recessão após as eleiçōes ${ }^{6}$. Assim, seria mais coerente supor que, ao invés de premiar com a reeleição o candidato que manipula a economia, o eleitor deveria puni-lo votando no seu oponente.

${ }^{6}$ De acordo com a inconsistência intertemporal de políticas ótimas proposta por Kydland e Prescott (1977). 


\subsection{Modelos Oportunistas com expectativas Racionais}

A partir dos anos 80 , alguns autores procuraram conciliar os modelos oportunistas à hipótese de expectativas racionais. Esses modelos atribuem a existência de ciclos político-econômicos à assimetria de informação entre os eleitores e os políticos, quanto à competência desses no comando do governo. Cada governante conduz a economia de forma mais ou menos competente, entretanto essa é uma informação privada, já que somente o próprio político sabe o seu potencial. Os eleitores observam os resultados das variáveis macroeconômicas para avaliar a competência do governante. Em virtude disso, os políticos tendem a agir oportunisticamente para parecer o mais competente possível a cada eleição, gerando os ciclos político-econômicos. As abordagens se diferenciam quanto à maneira com que os governantes utilizam os instrumentos macroeconômicos para demonstrar sua competência aos eleitores.

O modelo de Persson e Tabellini (1990) foi desenvolvido num ambiente econômico com preços rígidos, possibilitando a existência de um trade-off de curto prazo entre inflação e desemprego. Como se considera que a política monetária seja controlada diretamente pelo governante, este manipula tais instrumentos visando reduzir o desemprego aquém da sua taxa natural sem elevar o nível de preços. Contudo, nem todos os políticos terão sucesso nesta investida, apenas os verdadeiramente competentes. Essas hipóteses podem ser sintetizadas pela equação da curva de Phillips

$y_{t}=\bar{y}+\pi_{t}-\pi_{t}^{e}+\varepsilon_{t}$

onde $\pi_{t}$ é a taxa de inflação no período $\mathrm{t}$;

$\pi_{t}^{e}$ é a taxa de inflação esperada no período t;

$\bar{y}$ é a taxa de crescimento natural do produto;

$y_{t}$ é o taxa de crescimento do produto no período t;

$\varepsilon_{t}$ é a medida de competência do governante no período t.

Os ciclos político-econômicos são gerados pela assimetria de informação. O governante tenta parecer competente estimulando a atividade econômica através da política monetária expansionista perto das eleições. Os realmente competentes conseguirão elevar a taxa de crescimento do produto além do seu nível natural $\left(y_{t}>\bar{y}\right)$, porém os incompetentes, não. Como os votantes não têm informação de qual o tipo de político está no poder, formam suas expectativas de inflação a partir da média da inflação do competente (eleva- 
da) e do incompetente (baixa), ponderada pela probabilidade de cada um ser eleito. Conseqüentemente, a inflação verificada no àno da eleição será acima das expectativas- dos-eleitores, se o político for do tipo competente, e abaixo, caso seja incompetente.

Ao contrário de Persson e Tabellini (1990), que deram um tratamento keynesiano aos ciclos político-econômicos, ao basearem suas análises em curvas de Phillips de curto prazo e na eficácia de políticas monetárias expansionistas, Rogoff e Sibert (1988) elaboraram uma proposta alternativa sugerindo que, sob expectativas racionais, os ciclos político-econômicos devem ser observados nos instrumentos de política fiscal. De acordo com os autores, durante anos de eleição, os políticos tendem a reduzir os impostos e a elevar os gastos públicos, criando o que denominaram de ciclos políticos orçamentários (political budget cycles).

O modelo de ciclos políticos orçamentários desenvolvido por Rogoff e Sibert (1988) também é viabilizado pela existência de assimetria de informação entre políticos e eleitores. Os cidadãos desconhecem a capacidade do governante em administrar eficientemente os recursos públicos. Assim, para sinalizar sua competência, nos anos de eleição, o governante procura prover a maior quantidade de bens públicos possível e elevar o nível de utilidade dos eleitores.

Os ciclos políticos orçamentários ocorrem porque o governo possui uma vantagem temporária sobre os eleitores em relação às informações concernentes à produção de bens públicos e, portanto, da competência do administrador. Essa defasagem de tempo acontece porque há um custo elevado para os indivíduos monitorarem e avaliarem as açōes orçamentárias do governo, além de não se sentirem motivados para tomar tal atitude, já que podem estimar a competência do governante sem nenhum custo. Os resultados do modelo nos fazem concluir que, num ambiente com assimetria de informação, apenas o governante competente conseguirá aumentar os gastos públicos e reduzir os impostos antes das eleições, sinalizando seu tipo. O administrador incompetente não terá êxito na tentativa de mascarar a sua capacidade, adotando a política fiscal em condições de informação perfeita.

Para que os ciclos políticos orçamentários possam ser aliviados, Rogoff (1990) sugere a realização de modificações legais que restrinjam o uso dos instrumentos de política fiscal nos anos de eleição, como a adoção de planos orçamentários bienais. Outra possi- 
bilidade, diz respeito à mudança na estrutura eleitoral. O autor propõe que as eleições não sejam estabelecidas exogenamente, ao invés disso, acredita que deva haver um sistema no qual o governante possa convocar as eleições antes do final do mandato, a exemplo do que acontece em países como Japão, Canadá e Reino Unido.

Como podemos verificar, os modelos oportunistas com expectativas racionais chegam a uma conclusão um tanto quanto inconveniente, pois justamente os governantes mais competentes proporcionam maior instabilidade à economia, constituindo, assim, um problema de seleção adversa.

\subsection{Modelos Partidários com Expectativas Racionais}

A proposta dos modelos partidários tradicionais de que o partido no poder escolhe a combinação de inflação e desemprego ao longo do mandato condizente com a sua ideologia não se sustenta numa economia cujos agentes possuam expectativas racionais. Sob essa hipótese, as políticas econômicas implementadas somente terão efeitos sobre as variáveis reais se os agentes econômicos forem surpreendidos. Como os agentes têm conhecimento sobre o nível de inflação preferido pelos partidos, uma vez eleito o governante, os agentes econômicos incorporam essa informação na formação de expectativas e neutralizam os efeitos das políticas econômicas adotadas.

Ao reformular os modelos partidários tradicionais, Alesina (1987) partiu do princípio de que processos eleitorais justos têm por característica a incerteza quanto ao resultado da apuração. Por conseguinte, nos anos de eleição, mesmo os agentes dotados de expectativas racionais não saberão ao certo qual partido estará no poder no próximo ano e a forma que será conduzida a política econômica. Sendo assim, a taxa de inflação do período seguinte pode ser estimada a partir dos níveis de inflação de cada partido e as chances de vitória na eleiçāo.

O modelo elaborado por Alesina (1987) pressupõe que a uma economia seja caracterizada por uma curva de Phillips com expectativas racionais, na qual o governante tem pleno controle sobre os instrumentos de política econômica. Os trabalhadores negociam seus salários de forma sincronizada pelo período de um ano, visando obter um reajuste nominal que mantenha o seu poder de compra. 
Portanto, o produto da economia se desviará do produto de pleno emprego somente se as expectativas de inflação não se concretizarem

$y_{t}=\bar{y}+\left(\pi_{t}-w_{t}\right)$

onde $y_{t}=$ produto no ano t;

$\bar{y}=$ produto de pleno emprego;

$\pi_{t}=$ inflação do período t;

$w_{t}=$ salário nominal no período $\mathrm{t}$.

Em anos de eleição, como há a incerteza quanto ao futuro político, os trabalhadores acertam seus contratos salariais para o próximo período levando em consideração apenas as probabilidades de vitória de cada partido, perfeitamente observáveis nas pesquisas de intençōes de voto, sendo o histórico sobre o desempenho da economia totalmente irrelevante. A taxa de crescimento do salário nominal antes das eleições será determinada pela taxa de inflação esperada, estimada a partir das taxas de inflação esperadas dos partidos, ponderadas pelas chances de vitória de cada um, conforme a equação

$$
w_{t}=\pi_{t}^{e}=P E\left(\pi_{t}^{L}\right)+(1-P) E\left(\pi_{t}^{R}\right) \quad \text { com } 0<P<1
$$

onde $w_{t}=$ salário nominal no período $t$;

$\pi_{t}^{e}=$ inflação esperada no período $t$;

$P=$ probabilidade de vitória do partido de esquerda;

$(1-P)=$ probabilidade de vitória do partido de direita;

$E\left(\pi_{t}^{L}\right)=$ inflação esperada sob o governo do partido de esquerda;

$E\left(\pi_{t}^{R}\right)=$ inflação esperada sob o governo do partido de direita.

Como resultado do modelo, os partidos conseguem implementar as suas ideologias apenas no primeiro ano de mandato. Caso o partido de direita vença a eleição, o aumento do salário nominal dos trabalhadores será superior à taxa de inflação vigente $\left(w_{t}>\pi_{t}^{R}\right)$, as firmas irão demitir funcionários e a taxa de desemprego será maior do que a taxa natural. Por outro lado, se o partido de esquerda for eleito, a elevação do salário nominal dos trabalhadores será inferior à inflação vigente $\left(w_{t}<\pi_{t}^{L}\right)$, mais trabalhadores serão contratados e a taxa de desemprego será menor do que a taxa natural. Na próxima negociação salarial, com as expectativas revisadas, os trabalhadores reajustam seus salários no mesmo patamar do aumento do nível geral de preços e a economia será reconduzida ao pleno emprego. 


\section{Gráfico 3: Modelo Partidário com Expectativas Racionais de Alesina}

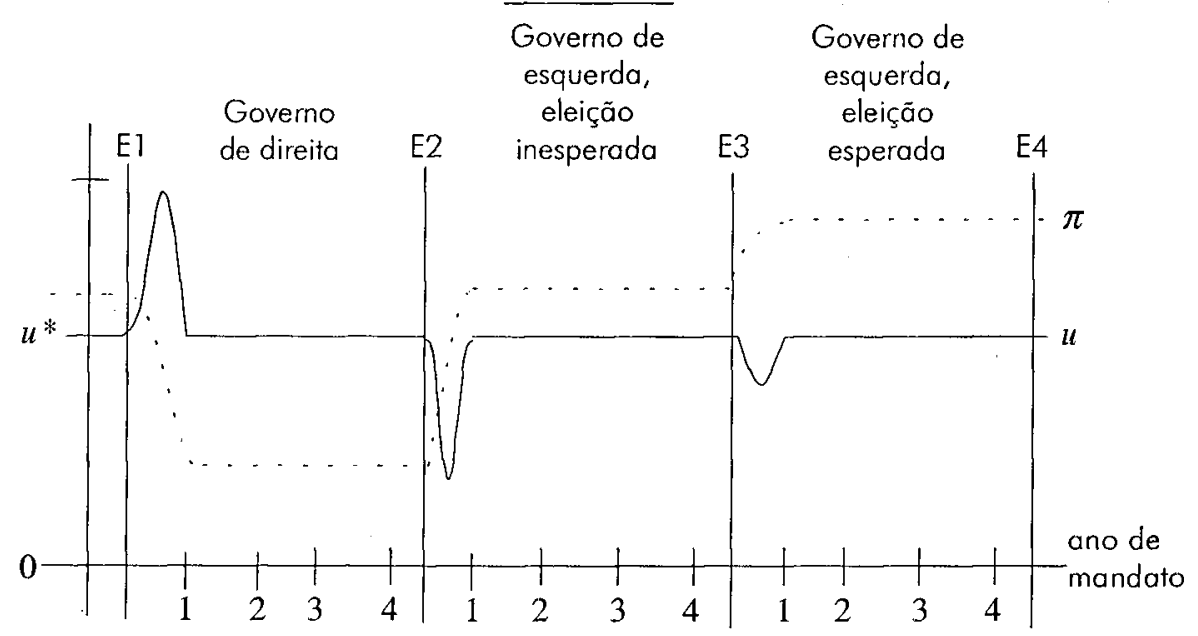

Conforme sintetizado no gráfico 3, a magnitude da flutuação do produto depende da previsibilidade do resultado da eleição. Por exemplo, se antes da data da votação (E2) as pesquisas apontam o candidato do partido de direita como favorito, os agentes econômicos, conhecendo a ideologia do partido, esperam uma taxa de inflação baixa para o ano seguinte. Supondo que o resultado das urnas contradiga as pesquisas e o candidato do partido de esquerda seja eleito, o governante conseguirá reduzir a taxa de desemprego $(u)$ abaixo da sua taxa natural no primeiro ano de mandato, sem, contudo, elevar o nivel geral de preços, pois as expectativas de inflação já haviam sido formadas. Posteriormente, à medida que os agentes econômicos reformulam suas expectativas, a taxa de inflação $(\pi)$ aumenta e a economia é reconduzida a sua taxa natural de desemprego $\left(u^{*}\right)$. Caso o resultado da eleição siga a tendência das pesquisas, como na eleição seguinte (E3), o impacto sobre o desemprego das políticas expansionistas implementadas pelo partido de esquerda será menor, pois os agentes já incorporaram essa informaçáo ao formarem suas expectativas de inflação.

Cabe ressaltar que a estrutura pluripartidária da política brasileira e a ocorrência de infidelidade ideológica inviabilizam a divisão bem definida entre "direita" e "esquerda", a exemplo do que ocorre nos Estados Unidos e em alguns países da Europa. Desta forma, ao realizarmos o estudo empírico a respeito dos ciclos político econômicos na economia brasileira, ficamos impossibilitados de testar a 
proposta dos modelos partidários. Sendo assim, a partir da seção seguinte enfocaremos apenas os modelos oportunistas.

\section{Estudos Empíricos de Ciclos Político-Econômicos}

Paralelamente à evolução dos modelos de ciclos político-econômicos, surgiram diversos trabalhos visando comprovar empiricamente os aspectos propostos pela teoria. Ao análisarmos a vasta literatura, podemos identificar dois grupos de testes empíricos. O primeiro deles concentra-se na avaliaçáo dos resultados macroeconômicos, tais como o crescimento do produto, o desemprego e a taxa de inflação. O segundo grupo enfoca os instrumentos de política econômica, como, por exemplo, emissão monetária, taxa de câmbio, arrecadação de impostos, transferências e gastos governamentais.

A maioria dos trabalhos que testaram a hipótese da existência dos ciclos político-econômicos oportunistas nas variáveis macroeconômicas para dados dos Estados Unidos, o rejeitaram, como McCallum (1978) e Alesina, Roubini e Cohen (1997) ${ }^{7}$. Num estudo mais abrangente, Alesina, Roubini e Cohen (1992) testaram a teoria dos ciclos político-econômicos para dezoito países desenvolvidos com regimes democráticos, entre 1960 e 1987. Para proceder o teste, utilizaram dados de painel para estimar modelos auto-regressivos do crescimento do produto e das taxas de desemprego e inflação, colocando variáveis dummy nos períodos eleitorais. A partir dos resultados gerais, rejeitaram a hipótese de ciclos oportunistas, contrariando as perspectivas do modelo de Nordhaus (1975).

Na estimação individual, Alesina, Roubini e Cohen (1992) detectaram ciclos eleitorais no crescimento do produto e na taxa de inflação em dois países, Nova Zelândia e Alemanha. No primeiro caso, não há novidade, pois o banco central neozelandês passou por uma reforma institucional no início dos anos 90, para adquirir maior independência. Contudo, o resultado da Alemanha é surpreendente, já que o Bundesbank é considerado o banco central com

\footnotetext{
${ }^{7}$ Ao comentarem esses resultados, Alesina e Sachs (1988) sugerem que a primeira administração do presidente Nixon foi a unica que se enquadrou às proposições do modelo de Nordhaus (1975). Já Rogoff (apud Drazen, 2000) foi mais longe e apelidou Nixon de "the all-time hero of political business cycle".
} 
maior grau de independência, se esperava que não houvesse manipulação pré-eleitoral na política monetária ${ }^{8}$.

Os modelos teóricos que propõem a existência de ciclos eleitorais na política fiscal sugerem que antes das eleições haja uma expansão do déficit público. Entretanto, não indicam explicitamente, se este aumento reflete a redução de impostos ou o aumento dos gastos do governo. Outra possibilidade é que, em anos eleitorais, ocorra uma transferência de recursos para projetos que tragam maiores benefícios políticos, não havendo necessariamente expansão do déficit público. Desta forma, os estudos empíricos usam diferentes variáveis para testar a presença de ciclos políticos oportunistas nos instrumentos de política fiscal.

Ao analisar a economia americana, Tufte (1978) aceitou a hipótese de ciclos oportunistas nas transferências privadas. Lockwood, Phillippopoulos e Snell (1996) encontraram evidências de manipulação dos gastos do governo, da arrecadação de impostos e do déficit público no Reino Unido, entre 1956 e 1993. Por outro lado, Ohlsson e Vredin (1996) rejeitaram a hipótese oportunista, ao testarem como a arrecadação e os gastos do governo foram influenciados pela atividade econômica, eleições e ideologia, na Suécia, entre os anos de 1968 e 1993.

Alguns autores procuraram testar a teoria dos ciclos políticoeconômicos para os países em desenvolvimento, baseados na crença de que nesses países os governantes tenham maior liberdade de manipular os instrumentos de política fiscal e monetária, devido ao fraco controle legal. Utilizando dados de painel de 35 países em desenvolvimento entre 1970 e 1992, Schuknet (1996) comprovou a ocorrência de ciclos oportunistas no déficit fiscal. Segundo o autor, esse aumento do déficit fiscal antes das eleições é gerado pela expansão dos gastos públicos, ao invés da redução da carga tributária.

Ao analisarmos a literatura existente sobre ciclos político-econômicos, pudemos perceber que há uma escassez de trabalhos publicados nesta área para o caso do Brasil. Este resultado chega a nos surpreender, tendo em vista que constantemente são apresentadas propostas para "amarrar as mãos" dos políticos a fim de que os mesmos não utilizem os instrumentos de política econômica para obter benefícios nas urnas. Entretanto, falta a estas propostas um embasamento empírico concreto.

${ }^{8}$ Berger e Woitek $(1996,1997)$ confirmaram esse resultado. 
Fialho (1997) adotou modelos auto-regressivos ao aplicar para o caso brasileiro os mesmos testes desenvolvidos por Alesina, Roubini e Cohen (1992), com exceção dos instrumentos-de política fiscal, justificando que, para esses dados, inexistem séries de tempo confiáveis e com periodicidade adequada. $\mathrm{O}$ estudo encontra evidências empíricas de ciclos políticos somente para o produto real bruto e para a emissão de moeda, entre os anos 1950 e 1995, concluindo que há uma tendência cíclica nos períodos eleitorais, resultante da expansão monetária.

No nosso entendimento, o argumento de Fialho (1997) para não realizar os testes com os instrumentos de política fiscal é fraco. Acreditamos que para verificar a ocorrência de ciclos político-econômicos no Brasil é fundamental proceder o teste para esses instrumentos. No caso do PIB real, o fato de ter sido utilizada uma série anual, com apenas 44 dados, e num período em que prevaleceu um regime ditatorial, torna as conclusões duvidosas. Além disso, Fialho (1997) rejeitou a hipótese para a taxa de desemprego, ferindo, assim, a princípios macroeconômicos básicos'. Para explicar a inconsistência de seus resultados, Fialho (1997) argumenta que o crescimento do produto na época das eleiçōes foi gerado pelo aumento da produtividade do trabalho, não pela redução do desemprego. Todavia, não é apresentado um teste que comprove essa peculiar relação entre a produtividade do trabalhador e o calendário eleitoral.

Paiva (1994) combina elementos dos modelos de ciclos político-econômicos e de modelos que explicam o comportamento e o impacto distributivo da regulação do governo em mercados específicos, para testar a relaçāo entre eleiçōes e preços regulados. A evidência empírica é obtida a partir da série de dados dos preços da gasolina no Brasil entre 1964 e 1984. Os resultados apresentados mostram que, em anos de eleição, houve uma queda no preço relativo da gasolina.

Bonomo e Terra (1999) apresentaram um estudo enfocando a influência política na condução da política cambial brasileira entre 1964 e 1997. Após testarem empiricamente, através de modelos de mudanças de Markov, Bonomo e Terra (1999), concluíram que a probabilidade de termos uma taxa de câmbio valorizada nos meses que precedem uma eleição é maior do que nos demais, enquanto que a probabilidade de haver desvalorização cambial nos meses

\footnotetext{
${ }^{9}$ Ver Lei de Okun.
} 
subseqüentes a uma eleição também é maior. Isto nos leva a crer que em períodos pré-eleitorais o governo adote um câmbio valorizado para satisfazer tanto os importadores como os consumidores, que podem consumir mais bens importados e viajar ao exterior. Outro resultado interessante desse trabalho foi a constatação de que durante o regime democrático os ciclos eleitorais mostraram-se mais expressivos do que na época da ditadura ${ }^{10}$, o que parece óbvio intuitivamente.

\section{Metodologia do Procedimento Econométrico}

Conforme predito pelos modelos de ciclos político-econômicos, ao analisarmos o comportamento de séries econômicas, poderemos constatar uma mudança no nível da série no período que precede as eleições, refletindo a atitude oportunista dos responsáveis pela política econômica. Desta forma, para testarmos a validade dessa proposta para dados do Brasil, decidimos adotar modelos auto-regressivos integrados de médias móveis (ARIMA) com variáveis dummy de intercepto nos meses que antecedem as eleições. Além do fato de grande parte dos trabalhos empíricos revisados terem utilizado tal metodologia, consideramos os modelos ARIMA mais adequados, pois são denominados modelos ateóricos, ou seja, não derivam de uma teoria econômica específica, e o comportamento das variáveis é explicado apenas por seus próprios valores defasados e pelos erros estocásticos. Assim, o modelo geral pode ser representado da seguinte forma

$z_{t}=\mu+\phi_{1} z_{t-1}+\phi_{2} z_{t-2}+\ldots . .+\phi_{p} z_{t-p}+u_{t}+\theta_{1} u_{t-1}+\theta_{2} u_{t-2}+\ldots . .+\theta_{q} u_{t-q}+\beta C P E$ (5.1)

onde $z_{t}=$ variável explicada;

$C P E=$ variável dummy para captar a manipulação pré-eleitoral, valendo 1 nos meses que antecedem às eleições e 0 nos demais meses;

$\mu=$ intercepto;

$\phi_{p}=$ parâmetro do componente auto-regressivo de ordem $p$;

$\theta_{q}=$ parâmetro do componente da média móvel de ordem $q$;

$u_{t}=$ resíduo .

${ }^{10}$ Cukierman e Meltzer (1992) denominaram a perda social por causa da manipulação préeleitoral de "custo da democracia" (cost of democracy). 
Seguindo a metodologia de Box-Jenkins ${ }^{11}$, a modelagem dos processos ARIMA obedece às seguintes etapas. Primeiramente, temos que identificar o modelo que descreve o comportamento da série temporal. Através dos testes de Dickey-Fuller Aumentado (ADF) ou de Phllip-Perron (PP), investigamos se a série apresenta raiz unitária. Caso a hipótese se confirme, devemos diferenciar a série até tornála estacionária. O provável número de defasagens dos componentes auto-regressivos e das médias móveis, bem como a necessidade de incluir componentes sazonais serão determinados pela análise do correlograma da série. Posteriormente, devemos estimar os modelos selecionados por mínimos quadrados ordinários e testarmos a significância estatística de seus parâmetros. Além disso, temos que proceder o teste $Q$ de Ljung-Box, para verificar se os resíduos são realmente ruído branco (white noise).

A escolha do modelo mais adequado obedecerá aos critérios de informação de Akaike (AIC) e de Schwartz (SIC) ${ }^{12}$. Cabe salientar que o coeficiente de determinação ajustado $\left(\bar{R}^{2}\right)$ não será observado como um critério para avaliar a qualidade do modelo estimado, pois conforme sugerido por Gujarati (1995): "In empirical analysis it is not unusual to obtain a very high $\bar{R}^{2}$ but find that some of the regression coefficients either are statistically insignificant or have signs that are contrary to a priori expectations." (Gujarati, 1995, p. 211 ). Assim, ao investigarmos a existência de ciclos oportunistas no Brasil, devemos nos preocupar com. a significância estatística dos parâmetros das variáveis que captam a manipulação pré-eleitoral e se o sinal destas confirma as proposições dos modelos teóricos ${ }^{13}$.

O motivo pelo qual limitamos o período a ser estudado entre os anos 1980 e 2000 reside no fato de que durante o regime militar o incentivo dos policymakers para agir de forma oportunista era muito pequeno. Mesmo com a realização de eleições para Congresso Nacional, acreditamos que o Governo já dispunha de poderes suficientes para controlar a situação política. Desta forma, no período a ser analisado, vamos considerar seis eleiçōes ${ }^{14}$. Entre elas as elei-

\footnotetext{
"Ver Enders (1995) e Hamilton (1994).

${ }^{12}$ De acordo com Enders (1995), ao selecionarmos o modelo que descreve o comportamento da série, devemos ser parcimoniosos, ou seja, temos que evitar a utilização de variáveis desnecessárias ao modelo (sobre parametrização).

${ }_{13}$ Para procedermos os testes econométricos utilizamos o programa Eviews 3.0.

${ }^{14}$ Foi exclúda a eleição indireta para Presidente da República realizada em janeiro de 1985.
} 
ções para os membros do Congresso Nacional de $1982^{15}, 1986$ e 1990, e as presidenciais de 1989, 1994 e 1998.

\section{Evidências de Oportunismo Político nas Variáveis Macroeconômicas no Brasil}

Os modelos de ciclos político-econômicos tradicionais sugerem que a atitude oportunista dos responsáveis pela política econômica pode ser constatada através da análise da trajetória das variáveis macroeconômicas. De acordo com esta concepção, nos anos eleitorais haveria uma tendência de crescimento do produto e redução das taxas de desemprego e de inflação para satisfazer as necessidades econômicas dos eleitores.

Para comprovarmos a ocorrência de ciclos oportunistas na atividade econômica brasileira, utilizamos as séries mensais do índice real do Produto Interno Bruto a preços de mercado, entre janeiro de 1980 e dezembro de 2000 , e da taxa de desemprego aberto do Instituto Brasileiro de Geografia e Estatística (IBGE), entre janeiro de 1980 e abril de 2001. No caso da taxa de inflação, usamos a série mensal do Índice Geral de Preços - Disponibilidade Interna (IGP-DI), de fevereiro de 1980 a dezembro de 2000 . Com o intuito de captar o oportunismo político, incluímos nos modelos as variáveis dummy CPEA e $\mathrm{CPEB}$, que assumem os valores 1 , nos 6 e 8 meses que antecedem a eleiçāo, respectivamente, e 0 , nos demais meses ${ }^{16}$.

Ao contrário do proposto pela teoria, os resultados das estimações não indicaram a existência dos ciclos político-econômicos no PIB a preços de mercado e na taxa de desemprego. Com relação à taxa de inflação, apesar de a análise gráfica indicar a não estacionariedade da série, o teste de Dickey-Fuller Aumentado (ADF) não confirmou a presença de raiz unitária ${ }^{17}$. Além disso, constata-

\footnotetext{
${ }^{15}$ Embora, tendo sido realizada ainda no regime militar, as eleições de 1982 foram inclúdas na amostra porque interessava ao governo vigente a obtenção da maioria das vagas no Colégio Eleitoral que elegeria o presidente da Nova República.

${ }^{16}$ Os dados foram obtidos no site www.ipeadata.com.br.

${ }^{17}$ De acordo com Cati, Garcia e Perron (1999), o teste de Dickey-Fuller Aumentado (ADF) não é o mais indicado para investigar a presença de raiz unitária em séries de inflação com sucessivas intervençōes governamentais. A série de inflação para o periodo até 1994 aparecia I(0) em função dos inliers, que representavam voltas para a média da distribuição. Contudo, fazendo o teste apropriado, com a incorporação das intervenções governamentais, a série de inflação torna-se I(1). Quando aplicamos o teste de Cati, Garcia e Perron (1999) para todo o período analisado, incluindo o Plano Real, que não foi por nós considerado um inlier, voltamos a ter o resultado de uma taxa de inflação $I(0)$.
} 
mos a ocorrência de quebras estruturais na trajetória da referida variável em virtude dos sucessivos planos de estabilização implementados durante o período. Sendo assim, incluímos uma variável dummy de intercepto (DUM) no modelo a ser testado, que assume os valores 1 , nos meses em que os planos de estabilização conseguem reduzir significativamente a inflação, e 0 , nos meses em que houve aceleração da inflação.

Depois de adotarmos os procedimentos descritos, selecionamos um modelo auto-regressivo de ordem 1, AR(1), para descrever o comportamento da taxa de inflação $(\pi)$. Desta forma, estimamos o modelo

$$
\pi_{t}=\mu+\phi_{1} \pi_{t-1}+\beta C P E+D U M+u_{t}
$$

De acordo com os resultados divulgados na tabela 1 , a variável CPEA foi aceita estatisticamente ao nível de significância de $5 \%$ e apresentou o sinal negativo, conforme proposto pela teoria. A variável inserida para captar as quebras estruturais (DUM) também foi considerada estatisticamente significativa e obteve o sinal negativo, indicando a queda abrupta da inflação nos meses em que os planos de estabilização obtiveram êxito. O resultado sugere que há uma tendência de queda da taxa de inflação nos 6 meses que antecedem as eleições. $O$ fato de termos encontrado evidências de oportunismo político na taxa de inflação, ao invés do produto e da taxa de desemprego, indica que a desutilidade marginal da inflação para o eleitor representativo brasileiro é maior do que a desutilidade marginal do desemprego. Essa característica das preferências econômicas do eleitor reflete as experiências inflacionárias traumatizantes da década de 80 e da primeira metade dos anos 90, o que leva os policymakers a concederem maior atenção ao controle dessa variável durante a época das eleições. 
Tabela 1: Resultados das Estimações dos Modelos da Taxa de Inflação

\begin{tabular}{|c|c|c|c|c|}
\hline Variável & Coeficiente & Estatística t* & Coeficiente & Estatística † \\
\hline$\mu$ & 20,10476 & $\begin{array}{c}6,177017 \\
(0,0000)\end{array}$ & 19,20375 & $\begin{array}{c}6,515301 \\
(0,0000)\end{array}$ \\
\hline$\pi_{t-1}$ & 0,905798 & $\begin{array}{c}33,90146 \\
(0,0000)\end{array}$ & 0,891689 & $\begin{array}{c}31,25351 \\
(0,0000)\end{array}$ \\
\hline$D U M$ & $-16,29556$ & $\begin{array}{c}-11,09495 \\
(0,0000)\end{array}$ & $-16,85203$ & $\begin{array}{c}-11,09260 \\
(0,0000)\end{array}$ \\
\hline$C P E A$ & $-5,861402$ & $\begin{array}{c}-4,114437 \\
(0,0001)\end{array}$ & & \\
\hline$C P E B$ & & & $-0,363510$ & $\begin{array}{c}-0,246421 \\
(0,8056)\end{array}$ \\
\hline $\bar{R}^{2}$ & 0,880099 & & 0,871923 & \\
\hline Durbin Watson & 2,197932 & & 2,163241 & \\
\hline Estatística $F$ & $\begin{array}{c}601,8969 \\
(0,0000)\end{array}$ & & $\begin{array}{c}558,2387 \\
(0,0000)\end{array}$ & \\
\hline A.I.C. & 5,960573 & & 6,026539 & \\
\hline
\end{tabular}

- Entre parênteses encontra-se a probabilidade do teste t bi-caudal.

\section{Evidências de Oportunismo Político nos Instrumentos de Política Econômica no Brasil}

Com a inclusão de expectativas racionais nos modelos de ciclos político-econômicos, a forma com que o oportunismo político se manifesta foi alterada. Sob essa condição, os ciclos oportunistas não devem ser observados através da análise das variáveis macroeconômicas, mas dos instrumentos de política econômica, meio pelo qual o governante sinaliza a sua competência aos eleitores. Desta forma, nos propomos a investigar a manipulação pré-eleitoral dos instrumentos de política fiscal e de política monetária no Brasil.

Para evidenciarmos a existência de ciclos oportunistas nos instrumentos de política fiscal do Brasil, usamos as séries de dados mensais da despesa total do Governo Federal e do déficit de caixa do Tesouro Nacional, de janeiro de 1980 a outubro de 2000, do gasto com pessoal e das transferências do Governo Federal aos estados e municípios, de janeiro de 1986 a outubro de $2000^{18}$. Não testamos

${ }^{18}$ Os dados foram obtidos nos Boletins do Banco Central. 
a hipótese de redução dos impostos nos meses que antecedem as eleições, pois acreditamos que a capacidade de manipulação desses instrumentos por parte do governante é limitada pela legislação tributária.

Ao realizarmos os testes econométricos que visam comprovar a existência de ciclos político-econômicos nas séries mensais da despesa total e do déficit fiscal do Tesouro Nacional, devemos ter cautela ao modelar as variáveis dummy que irão captar o oportunismo político. Como estes dados foram registrados pelo critério de caixa ao invés de competência, não podemos esperar o comportamento usual proposto pela teoria, pois o pagamento dos gastos do setor público envolve certos procedimentos burocráticos que geram uma defasagem de tempo entre o fato gerador da despesa e o seu efetivo pagamento ${ }^{19}$. Tendo em vista os incentivos que o arcabouço institucional thes concede, uma estratégia racional dos governantes é autorizar a realização dos serviços e a aquisição dos bens antes das eleições, postergando o pagamento para o mandato seguinte. Por esta razão, acreditamos que a despesa total e o déficit fiscal, quando contabilizados pelo critério de caixa, devem aumentar nos meses que sucedem as eleiçōes, ao contrário do que propõe a teoria.

Face ao exposto, para investigarmos a ocorrência de ciclos oportunistas na despesa total e no déficit fiscal, utilizamos quatro tipos de variáveis dummy. Seguindo o que foi proposto pelos modelos teóricos, as variáveis CPEA e CPEB assumem os valores 1, nos 6 e 8 meses que antecedem a votação, respectivamente, e 0 , nos demais meses. Por outro lado, levando em conta o processo burocrático que envolve o pagamento dos gastos do setor público, também testamos a mudança no nível da série após as eleiçōes, com as variáveis CPEC e CPED assumindo os valores 1 , nos 6 e 8 meses que sucedem à votação, respectivamente, e 0 , nos demais meses. Além disso, incluímos no modelo a série Produto Interno Bruto a preços de mercado (PIB) a fim de controlar a trajetória das variáveis.

Embora o déficit fiscal do Tesouro Nacional não tenha indicado a ocorrência de oportunismo político, a estimação do modelo autoregressivo da despesa total real (DESP) confirmou a hipótese de manipulação pré-eleitoral nessa variável. Os procedimentos da metodologia Box-Jenkins indicaram um processo auto-regressivo de

\footnotetext{
${ }^{19}$ Bacha (1994) utiliza esse argumento para justificar a existência de um efeito Olivera-Tanzi às avessas na economia brasileira durante a década de 80 .
} 
ordem 2 com componentes autoregressivos sazonais nas defasagens 12 e 24. Assim, estimamos o modelo

$$
D E S P_{t}=\mu+\phi_{1} D E S P_{t-1}+\phi_{2} D E S P_{t-2}+\phi_{12} D_{E S P_{t-12}}+\phi_{24} D_{E S P_{t-24}}+\alpha P I B+\beta C P E+u_{t}
$$

Como podemos observar na tabela 2 , os resultados das estimações não indicaram a existência de um ciclo oportunista na forma proposta pelos modelos teóricos, pois as variáveis dummy CPEA e CPEB não foram significativas. Entretanto, ao estimarmos o modelo com as variáveis dummy captando a mudança no nível da série após as eleições, as variáveis CPED e CPEC foram consideradas estatisticamente significativas a $5 \%$ e $15 \%$, respectivamente, e apresentaram o sinal positivo. Esse resultado sugere que as obrigações empenhadas antes do pleito foram liquidadas ao longo dos 8 meses que seguem as eleições, confirmando o que propusemos anteriormente. Para reforçar essa conclusão, em maio de 2000, foi instituída a Lei de Responsabilidade Fiscal, que, entre outras medidas, proíbe que o governante venha a contrair obrigação de despesa nos dois últimos quadrimestres do mandato que não possa ser cumprida integralmente dentro dele ou que tenha parcelas a serem pagas no exercício seguinte sem que haja suficiente disponibilidade de caixa.

Com relação aos demais instrumentos de política fiscal, rejeitamos a hipótese de oportunismo político. No caso dos gastos com pessoal, o resultado não chegou a surpreender, já que a legislação eleitoral impede a nomeação de servidores públicos nos 3 meses que antecedem a eleição. Além disso, acreditamos que a prática de proporcionar aumentos salariais visando obter benefícios eleitoras seria mais comum no âmbito estadual e municipal, nos quais essa medida atinge uma parcela considerável dos eleitores, ao contrário do Governo Federal que, para obter alguma vantagem nas urnas, deveria elevar o salário de um contingente enorme de funcionários.

Como já era previsto, não encontramos evidências de ciclos oportunistas no déficit fiscal pelo critério de caixa. Contestando a suposição dos modelos teóricos, acreditamos que essas variáveis não seriam boas fontes para captar o fenômeno. A atitude oportunista poderia acontecer sem que o governo incorresse necessariamente em déficits fiscais nos meses anteriores ao pleito. Por exemplo, o governante poderia poupar recursos ao longo do mandato, através de sucessivos superávits fiscais, que seriam gastos somente no último ano de governo. 
A série das transferências do Governo Federal aos estados e municípios disponível não é a mais indicada para investigarmos o oportunismo político. Entre as transferências, existe uma parcela obrigatória, que corresponde à parte da arrecadação de impostos que deve ser transferida aos estados e municípios, e outra voluntária, que depende do poder discricionário do governante central. Portanto, para chegarmos a um resultado mais conclusivo, deveríamos dispor de uma série das transferências voluntárias.

A respeito da manipulação pré-eleitoral dos instrumentos de política monetária, os modelos com expectativas racionais sugerem que a autoridade monetária adota medidas visando surpreender os agentes econômicos e, conseqüentemente, reduzir a taxa de desemprego antes da votação. No entanto, esses modelos não indicaram quais instrumentos deveriam ser analisados para visualizarmos tal comportamento. Geralmente, como pudemos verificar na revisão da literatura, os estudos empíricos utilizam o crescimento da oferta de moeda para comprovar a hipótese.

Tabela 2: Resultados das Estimações dos Modelos da Despesa Total

\begin{tabular}{|c|c|c|c|c|}
\hline Varióvel & Coeficiente & Estatística $\dagger$ & Coeficiente & Estatística $t$ \\
\hline$\mu$ & $-71,58507$ & $\begin{array}{c}-1,724311 \\
(0,0861)\end{array}$ & $-71,40081$ & $\begin{array}{c}-1,741969 \\
(0,0829)\end{array}$ \\
\hline$D E S P_{t-1}$ & 0,304971 & $\begin{array}{c}4,625670 \\
(0,0000)\end{array}$ & 0,296277 & $\begin{array}{c}4,475002 \\
(0,0000)\end{array}$ \\
\hline$D E S P_{t-1}$ & 0,245176 & $\begin{array}{c}3,687931 \\
(0,0003)\end{array}$ & 0,232729 & $\begin{array}{c}3,495993 \\
(0,0006)\end{array}$ \\
\hline$D E S P_{t-12}$ & 0,206249 & $\begin{array}{c}3,217823 \\
(0,0001)\end{array}$ & 0,211042 & $\begin{array}{c}3,297191 \\
(0,0011)\end{array}$ \\
\hline$D E S P_{t-24}$ & 0,359695 & $\begin{array}{c}5,614054 \\
(0,0088)\end{array}$ & 0,364898 & $\begin{array}{c}5,706056 \\
(0,0000)\end{array}$ \\
\hline$P I B$ & 1,585538 & $\begin{array}{c}4,308399 \\
(0,0000)\end{array}$ & 1,575331 & $\begin{array}{c}4,343274 \\
(0,0000)\end{array}$ \\
\hline$C P E A$ & $.4,839192$ & $\begin{array}{c}-0,868348 \\
(0,3862)\end{array}$ & & \\
\hline$C P E B$ & & & 0,805752 & $\begin{array}{c}0,158065 \\
(0,8746)\end{array}$ \\
\hline $\bar{R}^{2}$ & 0,551925 & & 0,550554 & \\
\hline Durbin Watson & 2,006339 & & 1,997713 & \\
\hline Estatística F & $\begin{array}{c}44,54892 \\
(0,0000)\end{array}$ & & $\begin{array}{c}44,30275 \\
(0,0000)\end{array}$ & \\
\hline A.l.C. & 9,153224 & & 9,156279 & \\
\hline
\end{tabular}




\begin{tabular}{|c|c|c|c|c|}
\hline Varióvel & Coeficiente & Estatística † $^{*}$ & Coeficiente & Estatística $t$ \\
\hline$\mu$ & $.75,56894$ & $\begin{array}{c}-1,947617 \\
(0,0528)\end{array}$ & $-77,71973$ & $\begin{array}{c}-1,974622 \\
(0,0496)\end{array}$ \\
\hline$D E S P_{t-1}$ & 0,276296 & $\begin{array}{c}4,149463 \\
(0,0000)\end{array}$ & 0,271433 & $\begin{array}{c}4,112255 \\
(0,0001)\end{array}$ \\
\hline$D E S P_{t-1}$ & 0,223409 & $\begin{array}{c}3,327881 \\
(0,0010)\end{array}$ & 0,244737 & $\begin{array}{c}3,682850 \\
(0,0003)\end{array}$ \\
\hline$D E S P_{t-12}$ & 0,206716 & $\begin{array}{c}3,208585 \\
(0,0015)\end{array}$ & 0,198745 & $\begin{array}{c}3,096075 \\
(0,0022)\end{array}$ \\
\hline$D E S P_{t-24}$ & 0,358789 & $\begin{array}{c}5,627027 \\
(0,0000)\end{array}$ & 0,368179 & $\begin{array}{c}5,795459 \\
(0,0000)\end{array}$ \\
\hline$P I B$ & 1,600174 & $\begin{array}{c}4,653857 \\
(0,0000)\end{array}$ & 1,609179 & $\begin{array}{c}4,624456 \\
(0,0000)\end{array}$ \\
\hline$C P E C$ & 8,624798 & $\begin{array}{c}1,558126 \\
(0,1207)\end{array}$ & & \\
\hline$C P E D$ & & & 11,16611 & $\begin{array}{r}2,206619 \\
(0,0284)\end{array}$ \\
\hline $\bar{R}^{2}$ & 0,555310 & & 0,560200 & \\
\hline Durbin Watson & 2,002122 & & 2,004234 & \\
\hline Estatística F & $\begin{array}{c}45,16346 \\
(0,0000)\end{array}$ & & $\begin{array}{c}46,06774 \\
(0,0000)\end{array}$ & \\
\hline A.I.C. & 9,145639 & & 9,134582 & \\
\hline
\end{tabular}

- Entre parênteses encontra-se a probabilidade do teste t bi-caudal.

No nosso entendimento, ao invés de procurarmos investigar o comportamento oportunista da autoridade monetária nos instrumentos de política monetária, devemos analisar a trajetória da variável que reflete essa atitude, a taxa de juros ${ }^{20}$. Como o objetivo do governante é aquecer a economia durante a campanha eleitoral, este somente será alcançado com a redução da taxa de juros.

Desta forma, estimamos um modelo auto-regressivo para a série da taxa de juros nominal - Over/Selic, entre janeiro de 1980 e setembro de 2000, disponiveis no Boletim do Banco Central do Brasil. Para captarmos a influência da eleição sobre a trajetória da taxa de juros (i), usamos as variáveis dummy CPEA e CPEB, que assumem os valores 1 , nos 6 e 8 meses que antecedem a votação, respectivamente, e 0 , nos demais meses. Como estamos utilizando a taxa de juros nominal, decidimos incluir a variável taxa de inflação $(\pi)$ no modelo para controlar a trajetória da série.

${ }^{20}$ Leertouwer e Maier (1999) também utilizaram a taxa de juros como uma proxy para verificar o opprtunismo político na condução da política monetária em 16 países $\mathrm{OECD}$. Os resultados não indicaram a existência de manipulação pré-eleitoral. 
Ao realizarmos o teste de Dickey-Fuller Aumentado (ADF) comprovamos que a série é estacionária. A análise do correlograma indicou um processo auto-regressivo de ordem 2. Depois de comparar os prováveis modelos pelo critério de informação de Akaike (AIC), decidimos estimar o modelo

$$
i_{t}=\mu+\phi_{1} i_{t-1}+\phi_{2} i_{t-2}+\beta C P E+\alpha \pi+u_{t}
$$

Os resultados das estimações apresentados na tabela 3 não indicaram a existência de ciclos oportunistas na trajetória da taxa de juros. As variáveis dummy testadas não foram consideradas estatisticamente significativas e os seus sinais não confirmaram o proposto pela teoria.

Tabela 3: Resultados das Estimações dos Modelos de Taxa de Juros

\begin{tabular}{|c|c|c|c|c|}
\hline Variável & Coeficiente & Estatística ${ }^{*}$ & Coeficiente & Estatística $†$ \\
\hline$\mu$ & 2,026030 & $\begin{array}{c}3,067129 \\
(0,0024)\end{array}$ & 1,874855 & $\begin{array}{c}2,843591 \\
(0,0048)\end{array}$ \\
\hline$i_{t-1}$ & 0,195372 & $\begin{array}{c}2,528287 \\
(0,0121)\end{array}$ & 0,189563 & $\begin{array}{c}2,464965 \\
(0,0144)\end{array}$ \\
\hline$i_{t-2}$ & 0,185425 & $\begin{array}{c}2,716298 \\
(0,0071)\end{array}$ & 0,179717 & $\begin{array}{c}2,636782 \\
(0,0089)\end{array}$ \\
\hline$\pi$ & 0,869068 & $\begin{array}{c}22,35320 \\
(0,0000)\end{array}$ & 0,873682 & $\begin{array}{c}23,03551 \\
(0,0000)\end{array}$ \\
\hline$C P E A$ & $-0,030869$ & $\begin{array}{c}-0,030637 \\
(0,9756)\end{array}$ & & \\
\hline$C P E B$ & & & 0,464783 & $\begin{array}{c}0,499880 \\
(0,6176)\end{array}$ \\
\hline $\bar{R}^{2}$ & 0,900709 & & 0,900809 & \\
\hline Durbin Watson & 1,989976 & & 1,989069 & \\
\hline Estatística F & $\begin{array}{l}546,5507 \\
(0,0000)\end{array}$ & & $\begin{array}{c}547,1644 \\
(0,0000)\end{array}$ & \\
\hline A.I.C. & 5,769958 & & 5,768947 & \\
\hline
\end{tabular}

Entre parênteses encontra-se a probabilidade do teste $\mathrm{t}$ bi-caudal.

\section{Considerações Finais}

Ao investigarmos o oportunismo político nas variáveis macroeconômicas, encontramos evidências apenas na taxa de inflação, descartando a hipótese para a taxa de desemprego e de crescimento do PIB. Conforme proposto pela teoria, os resultados indicaram uma tendência de queda da taxa de inflação nos 6 meses que 
antecedem as eleições. Como os responsáveis pela política econômica sabem que o eleitor tem grande aversão à inflação, eles concedem maior atenção ao controle dessa variável antes da votação.

$O$ fato de os policymakers do Brasil preferirem manipular a taxa de inflação ao invés do nível de atividade econômica também pode ser explicado pela facilidade de controle desta variável, durante o período em análise. Enquanto o governante tinha pouca capacidade para prever a defasagem de tempo necessária entre a adoção de medidas expansionistas e os seus efeitos, ele podia exercer o controle da inflação diretamente, através do congelamento de preços ou pelo adiamento dos aumentos de preços dos serviços públicos prestados pelas estatais, ou indiretamente, valorizando a taxa de câmbio antes das eleiçōes, conforme constatado por Bonomo e Terra (1999). Atualmente, ambos os tipos de controle são reduzidos, o direto, em virtude do processo de privatizaçōes, e o indireto, pois o impacto das desvalorizações cambiais sobre o nível de preços é menos significativo.

A respeito dos testes realizados para os instrumentos de política fiscal, verificamos a ocorrência de oportunismo político somente na despesa total do governo federal. Como os dados que utilizamos para proceder o estudo foram contabilizados pelo critério de caixa, ao invés de investigarmos o aumento dos gastos públicos no período que precede a eleição, tivemos que verificar a sua elevação após o pleito. Ao constatarmos que houve um aumento da despesa total nos 8 meses que sucedem as eleiçōes, concluímos que os governantes empenharam suas despesas antes da votação, postergando seu pagamento para o mandato seguinte. A Lei de Responsabilidade Fiscal, instituída para coibir esse tipo de comportamento, indica que essa prática era comum na administração pública, reforçando, assim, a conclusão do estudo empírico.

\section{Referências bibliográficas}

ALESINA, A. Macroeconomic Policy in a Two Party System as a Repeated Game. Quaterly Journal of Economics, v.102, p.651-78, 1987.

, ROUBINI, N. e COHEN, G. Political Cycles and the Macroeconomy. Cambridge, MA: MIT Press, 1997.

Democracies. In: CUKIERMAN, A., HERCOWITZ, Zvi e LEIDERMAN, I. (orgs.). 
Political Economy, Growth and Business Cycles. Cambridge, MA: MIT Press, 1992.

e SACHS, J. Political Parties and Business Cycle in the United States 19481984. Journal of Money, Creditand Banking, v.20, n.-1, p. 63-81, 1988.

BACHA, Edmar. O Fisco e a Inflação. Revista de Economia Política, v. 14, n. 1, janeiro/março, 1994.

BANCO CENTRAL DO BRASIL (1980-2001). Boletim Mensal, diversos volumes.

BERGER, Helge e WOITEK, Ulrich. Searching for Political Business Cycles in Germany. Public Choice, v.91, n. 2, p.179-197, 1997.

$\mathrm{e}$ . How Opportunistic Are Partisan German Central Bankers: Evidence on the Vaubel Hypothesis. European Journal of Political Economy, 1996. BONOMO, Marco e TERRA, Cristina. The Political Economy of Exchange Rate Policy in Brazil: 1964-1997. Textos para Discussão. Fundação Getúlio Vargas, Rio de Janeiro, março de 1999.

CATI, Regina Celia, GARCIA, Márcio e PERRON, Pierre. Unit Roots in the Presence of Abrupt Governmental Intervence with Application to Brazilian Data. Journal of Applied Econometrics, v.14 , n. 1, january/february, 1999.

CUKIERMAN, Alex e MELTZER, Allan. A Positive Theory of Discretionary Policy, The Cost of a Democratic Government and The Benefit of a Constitution. Economy Inquiry, n. 24, p.367-388, 1986.

DOWNS, A. An Economic Theory of Political Action in a Democracy. Journal of Political Economy, v. 65, n. 2, p.135-50, abril de 1957.

DRAZEN, A. The Political Business Cycle After 25 Years. National Bureau of Economic Research, 2000.

ENDERS, Walter. Applied Econometric Time Series. John Wiley \& Sons, Inc. 1995. FIALHO, Tânia. Testando a Evidência de Ciclos Políticos no Brasil. Revista Brasileira de Economia, v.51, n. 3, p. 379-389, julho - setembro de 1997.

GUJARATI, Damodar. Basic Econometrics. 3 ed. New York: McGraw-Hill, 1995.

HAMILTON, James. Time Series Analysis. Princeton: Princeton University Press, 1994.

HIBBS, D. Political Parties and Macroeconomic Policies and Outcomes in the United States. American Economic Review Papers and Proceedings, v.76, n. 2, p.6670, 1986.

. Political Parties and Macroeconomic Policy, American Political Science Review, v.71, p.1467-87, 1977.

LEERTOUWER, Erik e MAIER, Philipp. International and Domestic Constraints on PBC's in OECD Economies: a Comment. CCSO Quaterly Journal, University of Groningen, v.1, n. 4, dec/1976. 
LINDBECK, A. Stabilization Policies with Open Economies and Endogenous Politicians. American Economic Review Papers and Proceedings, p.1-19, 1976.

LOCKWOOD, B., PHILLIPPOPOULOS, A. e SNELL, A. Fiscal Policy, Public Debt Stabilization and Politics: Theory and United Kingdom Evidence. The Economic Journal, v.106, p. 894-911, julho de 1996.

McCALLUM, B. Political Business Cycle: An Empirical Test. Southern Economic Journal, v. 44, p. 504-15, 1978.

McRAE, C. D. A Political Model in Business Cycle. Journal of Political Economy, v.85, n. 2, p.239-263, 1977.

NORDHAUS, W. The Political Business Cycle. Review of Economic Studies, v. 42, p.169-90, 1975.

OHLSSON, H. e VREDIN, A. Political Cycles and Cyclical Policies. Scandinavian Journal of Economics, v.98, n. 2, p. 203-18, 1996.

PAIVA, Cláudio. Interesses Eleitorais e Flutuações de Preços em Mercados Regulados. Revista de Economia Política, v. 4, n. 56, p. 31-40, 1994.

PERSSON, T. e TABELLINI, G. Macroeconomic Policy, Credibility, and Politics, Chur, Switzerland: Harwood Academic Publishers, 1990.

$\mathrm{e}$ . Macroeconomic Policy, Credibility, and Politics, Chur, Switzerland: Harwood Academic Publishers, 1990.

ROGOFF, Kenneth. Equilibrium Political Budget Cycles. American Economic Review, v.80, n.1 , p.21-36, março de 1990.

e SIBERT, A. Elections and Macroeconomic Policy Cycles. Review of Economic Studies, v.55, p.1-16, 1988.

SCHUKNECHT, L. Political Business Cycles in Developing Countries. Kyklos, v.49, n. 2, p. 155-70, 1996.

TUFTE, E. Political Control of the Economy. Princeton, N. J.: Princeton University Press, 1978. 